\title{
An improved parameterization for sulfuric acid-water nucleation rates for tropospheric and stratospheric conditions
}

\author{
H. Vehkamäki, ${ }^{1}$ M. Kulmala, ${ }^{1}$ I. Napari, ${ }^{1}$ K. E. J. Lehtinen, ${ }^{1}$ C. Timmreck, ${ }^{2}$ \\ M. Noppel, ${ }^{3,4}$ and A. Laaksonen ${ }^{5}$ \\ Received 7 February 2002; revised 25 March 2002; accepted 29 March 2002; published 19 November 2002.
}

[1] In this paper we present parameterized equations for calculation of sulfuric acidwater critical nucleus compositions, critical cluster radii and homogeneous nucleation rates for tropospheric and stratospheric conditions. The parameterizations are based on a classical nucleation model. We used an improved model for the hydrate formation relying on ab initio calculations of small sulfuric acid clusters and on experimental data for vapor pressures and equilibrium constants for hydrate formation. The most rigorous nucleation kinetics and the thermodynamically consistent version of the classical binary homogeneous nucleation theory were used. The parameterized nucleation rates are compared with experimental ones, and at room temperature and relative humidities above $30 \%$ they are within experimental error. At lower temperatures and lower humidities the agreement is somewhat poorer. Overall, the values of nucleation rates are increased compared to a previous parameterization and are within an order of magnitude compared with theoretical values for all conditions studied. The parameterized equations will reduce the computing time by a factor 1/500 compared to nonparameterized nucleation rate calculations and therefore are in particular useful for large-scale models. The parameterized formulas are valid at temperatures between $230.15 \mathrm{~K}$ and $305.15 \mathrm{~K}$, relative humidities between $0.01 \%$ and $100 \%$, and sulfuric acid concentrations from $10^{4}$ to $10^{11}$ $\mathrm{cm}^{-3}$. They can be used to extrapolate the classical results down to $190 \mathrm{~K}$. The parametrization is limited to cases where nucleation rates are between $10^{-7}$ and $10^{10}$ $\mathrm{cm}^{-3} \mathrm{~s}^{-1}$, and the critical cluster contains at least four molecules. INDEX TERMS: 0305 Atmospheric Composition and Structure: Aerosols and particles (0345, 4801); 1610 Global Change: Atmosphere (0315, 0325); 0365 Atmospheric Composition and Structure: Troposphere-composition and chemistry; KEYWORDS: nucleation, sulfuric acid, water, aerosol formation

Citation: Vehkamäki, H., M. Kulmala, I. Napari, K. E. J. Lehtinen, C. Timmreck, M. Noppel, and A. Laaksonen, An improved parameterization for sulfuric acid-water nucleation rates for tropospheric and stratospheric conditions, J. Geophys. Res., 107(D22), 4622, doi:10.1029/2002JD002184, 2002.

\section{Introduction}

[2] Sulfate aerosols play an important role in the Earth's climate system and in atmospheric chemistry. They scatter solar radiation back to space, thereby cooling the atmosphere and act as condensation and ice nuclei for the formation of clouds, one of the most important elements in the climate system. Sulfate aerosols are formed in the atmosphere due to secondary particle production, i.e., homogeneous nucleation from sulfuric acid and water, and

\footnotetext{
${ }^{1}$ Department of Physical Sciences, University of Helsinki, Helsinki, Finland.

${ }^{2}$ Max-Planck Institut für Meteorologie, Hamburg, Germany.

${ }^{3}$ Institute of Environmental Physics, Tartu, Estonia.

${ }^{4}$ Also at Department of Physical Sciences, University of Helsinki, Helsinki, Finland.

${ }^{5}$ Department of Applied Physics, University of Kuopio, Kuopio, Finland.

Copyright 2002 by the American Geophysical Union. 0148-0227/02/2002JD002184
}

by the possible participation of other species like ammonia [Korhonen et al., 1999; Kulmala et al., 2000].

[3] New particle formation has been observed in situ in various parts of the atmosphere: in the marine boundary layer [Covert et al., 1992; Hoppel et al., 1994; O'Dowd et al., 1998], in the vicinity of evaporating clouds [Hegg et al., 1991; Wiedensohler et al., 1997], in Arctic areas [Shaw, 1989; Wiedensohler et al., 1996; Pirjola et al., 1998] and in forests [Kavouras et al., 1998; Kulmala et al., 2001].

[4] Observations have also shown that new particle formation takes place also in the upper troposphere and in the stratosphere. A large number of small particles have been observed in the remote free troposphere [Clarke, 1992, 1993], in the upper tropical troposphere [Brock et al., 1995], near the tropopause [Schröder and Ström, 1997; De Reus et al., 1998] and in the polar lower stratosphere in the springtime [Wilson et al., 1989]. A large-scale nucleation event has also been detected during the Subsonic Assessment: Contrails and Clouds Effects Special Study (SUCCESS) campaign in the vicinity of a deep convective storms in the midlatitude upper troposphere [Twohy et al., 2002; 
Clement et al., 2002]. These observations suggest that new particles are formed in the upper regions of the atmosphere due to low temperatures, intensive sunlight and low preexisting number concentration. Homogeneous nucleation of sulfuric acid and water has turned out to be an important process for stratospheric aerosol formation in a volcanically disturbed atmosphere. After the eruption of Mt. Pinatubo an increase of 1-2 orders of magnitude in the concentration of condensation nuclei in the volcanic layers was found [Deshler et al., 1992]. 98\% of the observed aerosol was volatile [Deshler et al., 1993; Sheridan et al., 1992].

[5] There is an ongoing effort to include fully explicit size-resolving sulfate aerosol microphysics in global models. These models cover a wide range from two dimensional models [Bekki and Pyle, 1992; Tie et al., 1994; Weisenstein et al., 1997], to three dimensional chemistry transport models [Pitari et al., 2002]. Recently also regional models [Schell et al., 2001] and global-scale models [Timmreck, 2001; Wilson et al., 2001] with explicit aerosol dynamics are developed.

[6] In large-scale models which consider aerosol dynamics, it is often necessary to use parameterized nucleation rates in order to save computing time. We have therefore recently introduced a parameterization for sulfuric acidwater nucleation rates for tropospheric conditions [Kulmala et al., 1998]. However, this parameterization is valid only between $233 \mathrm{~K}$ and $298 \mathrm{~K}$ and for relative humidities between $10 \%$ and $100 \%$ and can not be applied globally. This is particularly critical for the upper tropical troposphere with temperatures below $200 \mathrm{~K}$ which is a preferred region for homogeneous nucleation. It is therefore necessary to extend our parameterization to lower temperatures and lower humidities to cover all altitudes from the boundary layer to the stratosphere.

[7] Although new theoretical approaches [Laaksonen and Oxtoby, 1995; Arstila et al., 1998; Kusaka et al., 1998] have been developed in the last years, the classical nucleation theory [Seinfeld and Pandis, 1998] is still the only approach which can be used in atmospheric applications, particularly in atmospheric models. The more sophisticated nucleation models rely on potentials describing realistically the interactions between nucleating molecules. Reliable potentials exist for ideal substances like argon, and partially satisfactory models have been developed for pure water, but for other atmospheric molecules the potential construction is incomplete.

[8] It is important to make sure that the predictions using the classical theory are made using thermodynamically consistent theories with detailed thermodynamics [Korhonen et al., 1997; Clegg et al., 1998]. However, molecular approaches are needed to confirm the results obtained by classical theories. We have recently investigated the homogeneous nucleation of sulfuric acid and water under atmospheric conditions using the most rigorous nucleation kinetics, the thermodynamically consistent version of the classical nucleation model and an improved model for the formation of sulfuric acid water hydrates [Noppel et al., 2002]. This improved model for hydrate formation in sulfuric acid-water nucleation is based on ab initio calculations of small sulfuric acid clusters and on experimental data for vapor pressures and equilibrium constants [Noppel et al., 2002; Noppel, 2000]. It was shown [Noppel et al.,
2002] that the nucleation rates derived with the revised theory are in most cases within the observational error. The values are however higher compared to our old parameterization [Kulmala et al., 1998]. The differences can be explained by several approximations in the old parameterization which are partly erroneous in the kinetic part. In addition the activity coefficients [Taleb et al., 1996] which are used in the old parameterization [Kulmala et al., 1998] deviate significantly from the experimental values in some cases.

[9] Here we will present a new and revised parameterization for the binary homogeneous nucleation rate of sulfuric acid and water for tropospheric and stratospheric conditions as an extension of our old parameterization for tropospheric conditions [Kulmala et al., 1998]. The theoretical model of the classical nucleation theory and the improved hydrate interaction model is outlined in section 2. In section 3 we briefly describe the applied thermodynamic quantities. In section 4 the new parameterizations are presented. In section 5 the present results are compared to laboratory experiments and our old parameterization by Kulmala et al. [1998]. Section 6 summarizes the results.

\section{Theory and Model}

[10] Here we will give only a brief overview of the classical nucleation theory. For a more detailed description the reader is referred to our earlier work [Kulmala et al., 1998; Noppel et al., 2002] and references therein.

[11] Nucleation is formation of supercritical stable clusters. The critical cluster can be identified by finding the maximum of the formation free energy with respect to number of water and acid molecules. The critical cluster composition can be solved from the equation

$$
v_{\mathrm{w}}\left(x^{*}\right) \ln \frac{\rho_{\mathrm{a}}^{\mathrm{free}}}{\rho_{\mathrm{a}, \mathrm{s}}^{\text {free }}\left(x^{*}\right)}=v_{\mathrm{a}}\left(x^{*}\right) \ln \frac{\rho_{\mathrm{w}}^{\mathrm{free}}}{\rho_{\mathrm{w}, \mathrm{s}}^{\text {free }}\left(x^{*}\right)},
$$

where $v_{a}$ and $v_{w}$ are the composition dependent partial molar volumes of acid and water, respectively. $\rho_{i}^{\text {free }}$ is the number concentration of free molecules of component $i$ in the nucleating vapor and $\rho_{i, s}^{\text {free }}(x)$ is the number concentration of component $i$ in saturated vapor above a solution with sulfuric acid mole fraction $x$. The asterisk refers to the critical cluster.

[12] Sulfuric acid tends to form hydrates in the vapor phase. These small clusters of acid and water molecules have negative formation energy, they stabilize the vapor and hinder nucleation. In nucleation experiments the total concentration of sulfuric acid molecules (containing also the acid molecules bound in hydrates) is measured, but the concentration of free acid molecules (not bound to hydrates) enters the nucleation energetics (e.g. via equation (1)). The number concentrations of $i$-hydrates $\rho(1, i)$ are given by [Alberty, 1983]

$$
\rho(1, i)=K_{1} \cdot K_{2} \ldots \cdot K_{i}\left(\frac{\rho_{\mathrm{w}}^{\text {free }}}{\rho_{0}}\right)^{i} \rho_{\mathrm{a}}^{\text {free }}
$$

where $K_{i}$ are the equilibrium constants for the successive additions of water molecules to an acid molecule. Their 
temperature dependent values are given by Noppel et al. [2002]. The equilibrium constants are calculated at a reference vapor concentration $\rho_{0}=p_{0} /(k T)$ where the reference pressure $p_{0}$ is set to $1 \mathrm{~atm}, T$ is the temperature and $k$ is the Boltzmann constant. The ratio of the total acid concentration to the number concentration of free acid molecules in the gas phase is [Jaecker-Voirol et al., 1987; Noppel, 1998]

$$
\begin{aligned}
& \frac{\rho_{\mathrm{a}}^{\text {free }}}{\rho_{\mathrm{a}}^{\text {free }}}=1+K_{1} \frac{\rho_{\mathrm{w}}^{\text {free }}}{\rho_{0}}+\cdots \\
& +K_{1} \cdot K_{2} \ldots \cdot K_{i}\left(\frac{\rho_{\mathrm{w}}^{\text {free }}}{\rho_{0}}\right)^{i}+\cdots \\
& +K_{1} \cdot K_{2} \ldots \cdot K_{N}\left(\frac{\rho_{\mathrm{w}}^{\text {free }}}{\rho_{0}}\right)^{N}
\end{aligned}
$$

Here $N$ is the number of water molecules in the largest hydrate taken into account and $\rho_{\mathrm{a}}^{\text {total }}$ is the total number concentration of sulfuric acid molecules in the vapor phase, including the ones bound in hydrates. We assume that the concentrations of hydrates with more than one acid molecule are negligible, and that the concentration of water vapor is not significantly affected by the hydrate formation $\left(\rho_{\mathrm{w}}^{\text {free }}=\rho_{\mathrm{w}}^{\text {total }}\right)$.

[13] The radius of the critical cluster is given by the Kelvin equation

$$
r^{*}=\frac{2 \sigma\left(x^{*}\right) v_{i}\left(x^{*}\right)}{k T \ln \left(\rho_{i}^{\text {free }} / \rho_{i, \mathrm{~s}}^{\mathrm{free}}\left(x^{*}\right)\right)},
$$

where $\sigma$ is the surface tension of the solution. Equation (1) ensures that the value of $r^{*}$ is independent of the choice of the component $i=\mathrm{a}, \mathrm{w}$. The work of formation for the critical nucleus is

$$
W^{*}=\frac{4}{3} \pi r^{* 2} \sigma\left(x^{*}\right)
$$

and the general expression for nucleation rate $J$ is [Trinkaus, 1983; Arstila et al., 1999]

$$
J=Z \cdot \rho(1,2) \cdot \exp \left[\frac{-\left(W^{*}-W(1,2)\right)}{k T}\right]
$$

where $\rho(1,2)$ and $W(1,2)$ are, respectively, the number concentration and the formation energy of a sulfuric acid dihydrate, and $Z$ is a kinetic pre-factor. The product of the two last terms is the equilibrium concentration of critical nuclei [Noppel et al., 2002]. Here we use the dihydrate (one sulfuric acid bound to two water molecules) as a reference size. Any other cluster size, whose formation energy is known from experiments and/or ab initio calculations could alternatively be chosen as the reference point for the distribution.

\section{Thermodynamical Parameterizations}

[14] In order to solve the composition and the radius of the critical cluster and subsequently to calculate the nucle- ation rate we need to know the surface tension, density of the solution as well as the equilibrium vapor pressures of sulfuric acid and water above a flat surface of the solution. For pure water we use the saturation vapor pressure $\left(\mathrm{Nm}^{-2}\right.$, $T$ in K) according to Preining et al. [1981]

$$
\begin{aligned}
p_{w}= & \exp \{77.34491296-7235.424651 / T-8.2 \ln T \\
& \left.+5.7113 \cdot 10^{-3} T\right\}
\end{aligned}
$$

and for sulfuric acid vapor pressure $\left(\mathrm{Nm}^{-2}, T\right.$ in $\left.\mathrm{K}\right)$ we use the formula based on the work of Ayers et al. [1980], which is corrected for lower temperatures by Kulmala and Laaksonen [1990]:

$$
\begin{aligned}
p_{\mathrm{a}}= & 101325 \exp \left\{L+10156\left[\frac{1}{360.15}-\frac{1}{T}+\frac{0.38}{545}\right.\right. \\
& \left.\left.\cdot\left(1+\ln \left(\frac{360.15}{T}\right)-\frac{360.15}{T}\right)\right]\right\}
\end{aligned}
$$

The value of the parameter $L=-11.695$ was fitted to various experimental and $\mathrm{ab}$ initio data in our recent paper [Noppel et al., 2002].

[15] We fitted a polynomial form to the experimental surface tension data of Sabinina and Terpugow [1935], Morgan and Davies [1916], Suggitt et al. [1949], Hoffmann and Seeman [1960], and Myhre et al. [1998] in the temperature range $233-323 \mathrm{~K}$. The experimental data points of Myhre et al. [1998] with sulfuric acid mass fraction 0.291 deviate for the trend of other points, and they were not used in the fitting. The following fit gives the surface tension $\sigma$ $\left(\mathrm{J} / \mathrm{m}^{2}\right)$ for all sulfuric acid mass fractions $x_{m}$ where the solution is liquid:

$$
\sigma\left(x_{m}, T\right)=a\left(x_{m}\right)+T b\left(x_{m}\right)
$$

where the coefficients are given by

$$
\begin{aligned}
a\left(x_{m}\right)= & 0.11864-0.11651 x_{m}+0.76852 x_{m}^{2}-2.40909 x_{m}^{3} \\
& +2.95434 x_{m}^{4}-1.25852 x_{m}^{5} \\
b\left(x_{m}\right)= & -0.00015709+0.00040102 x_{m}-0.00239950 x_{m}^{2} \\
& +0.007611235 x_{m}^{3}-0.00937386 x_{m}^{4}+0.00389722 x_{m}^{5}
\end{aligned}
$$

[16] The experiments of Myhre et al. [1998] are the only ones conducted at temperatures below $273.15 \mathrm{~K}$. To illustrate the validity of our surface tension expression at the low temperatures stratosphere and upper troposphere, Figure 1 shows the comparison between our surface tension fit and the experimental data of Myhre et al. [1998].

[17] Density data $\rho\left(\mathrm{g} / \mathrm{cm}^{3}\right)$ for the sulfuric acid solution at 273-373 K from the National Research Council [1928] are fitted to a polynomial function:

$$
\rho\left(x_{m}, T\right)=a\left(x_{m}\right)+b\left(x_{m}\right) T+c\left(x_{m}\right) T^{2}
$$




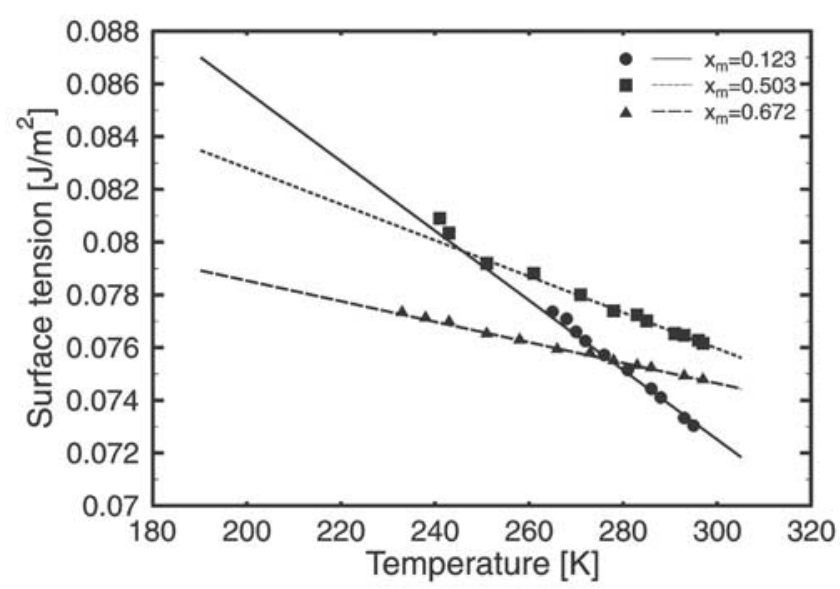

Figure 1. Comparison between the surface tension parameterization (lines) and the experimental surface tension data of Myhre et al. [1998] (symbols). Different lines types and symbols represent different mass fractions $x_{m}$ of sulfuric acid in the liquid.

[18] Here $T$ is temperature of the liquid and $x_{m}$ is the mass fraction of sulfuric acid. The coefficients $a\left(x_{m}\right), b\left(x_{m}\right)$ and $c\left(x_{m}\right)$ are obtained from the following equations:

$$
\begin{aligned}
a\left(x_{m}\right)= & 0.7681724+2.1847140 x_{m}+7.163002 x_{m}^{2}-44.31447 x_{m}^{3} \\
& +88.75606 x_{m}^{4}-75.73729 x_{m}^{5}+23.43228 x_{m}^{6} \\
b\left(x_{m}\right)= & 1.808225 \cdot 10^{-3}-9.294656 \cdot 10^{-3} x_{m}-0.03742148 x_{m}^{2} \\
& +0.2565321 x_{m}^{3}-0.5362872 x_{m}^{4}+0.4857736 x_{m}^{5} \\
& -0.1629592 x_{m}^{6} \\
c\left(x_{m}\right)= & -3.478524 \cdot 10^{-6}+1.335867 \cdot 10^{-5} x_{m} \\
& +5.195706 \cdot 10^{-5} x_{m}^{2}-3.717636 \cdot 10^{-4} x_{m}^{3} \\
& +7.990811 \cdot 10^{-4} x_{m}^{4}-7.458060 \cdot 10^{-4} x_{m}^{5} \\
& +2.58139 \cdot 10^{-4} x_{m}^{6} .
\end{aligned}
$$

This fit also reproduces well the low temperature (220K300K) densities reported by Myhre et al. [1998] as shown in Figure 2.

[19] Activity coefficients for the water-sulfuric acid solution are crucial parameters in the nucleation calculations [Taleb et al., 1996; Clegg et al., 1998]. The most rigorous method for evaluating the activity coefficients has been presented by Clegg and Brimblecombe [1995] and Clegg et al. [1998]. It includes ionic solutes, and gives the measured thermodynamic properties quite accurately. However, from a computational point of view, it is slow and valid only up to a sulfuric acid mole fraction of 0.42 . In a recent study [Noppel et al., 2002] we have compared the thermodynamic model of Clegg and Brimblecombe [1995] and Clegg et al. [1998] with the liquid phase activity model of Zeleznik [1991]. We have shown that the resulting hydrate distributions and nucleation rates do not differ significantly. For our parameterization we will use the activity coefficients by Zeleznik [1991] because their formulation saves computer time and is valid also at high sulfuric acid concentrations found in critical nuclei.

\section{Nucleation Parameterizations}

[20] The parameterization is valid for the temperature range $230.15-300.15 \mathrm{~K}$, relative humidities $0.01-100 \%$ and total sulfuric acid concentrations $10^{4}-10^{11} / \mathrm{cm}^{3}$. These limit have been set by atmospheric conditions and the thermodynamical data described in the previous section. To allow nucleation calculations in the conditions of upper troposphere and stratosphere we have extended our parameterization down to the temperature $190 \mathrm{~K}$. This involves extrapolations of thermodynamical data outside the experimental regions. Figures 1 and 2 show that the surface tension and density parameterizations behave smoothly even below $230 \mathrm{~K}$. The fit is only valid at a region where it produces nucleation rates in the range $10^{-7}-10^{10} 1 /\left(\mathrm{cm}^{3} \mathrm{~s}\right)$ and the total number of molecules in the critical cluster given by equation (13) is at least 4 . Also the cases where the critical cluster would be a hydrate (clusters with one sulfuric acid and 1-5 water molecules) are excluded from the region of validity. Note that when using the fit for mole fraction and nucleation rate it is important to use also equation (13) to check that these restrictions on cluster size are not violated.

[21] The mole fraction of sulfuric acid in the critical cluster is given by

$$
\begin{aligned}
x^{*}= & 0.740997-0.00266379 T \\
& -0.00349998 \ln \left(N_{a}\right)+0.0000504022 T \ln \left(N_{a}\right) \\
& +0.00201048 \ln \left(\frac{R H}{100}\right)-0.000183289 T \ln \left(\frac{R H}{100}\right) \\
& +0.00157407\left[\ln \left(\frac{R H}{100}\right)\right]^{2}-0.0000179059 T\left[\ln \left(\frac{R H}{100}\right)\right]^{2} \\
& +0.000184403\left[\ln \left(\frac{R H}{100}\right)\right]^{3}-1.50345 \cdot 10^{-6} T\left[\ln \left(\frac{R H}{100}\right)\right]^{3},
\end{aligned}
$$

where $N_{a}$ is the total gas phase concentration of sulfuric acid $\left(1 / \mathrm{cm}^{3}\right), T$ is the absolute temperature and $R H$ is the relative humidity in percent.

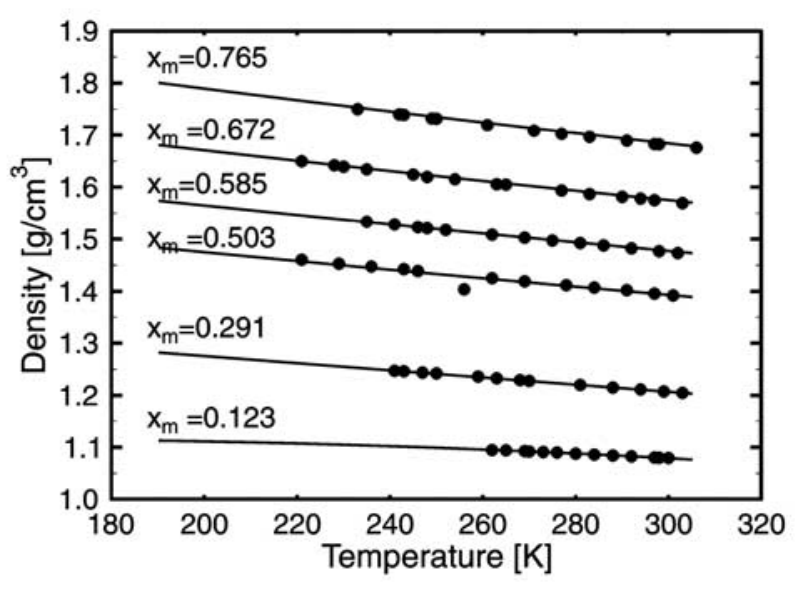

Figure 2. Comparison between the density parameterization (lines) and the experimental density data of Myhre et al. [1998] (dots). Different lines represent different mass fractions of sulfuric acid in the liquid. 
[22] The nucleation rate is given by an exponential of a third order polynomial of $\ln (R H / 100)$ and $\ln \left(N_{a}\right)$

$$
\begin{aligned}
& J\left[1 /\left(\mathrm{cm}^{3} \mathrm{~s}\right)\right]=\exp \left\{a\left(T, x^{*}\right)+b\left(T, x^{*}\right) \ln (R H / 100)\right. \\
& +c\left(T, x^{*}\right)[\ln (R H / 100)]^{2}+d\left(T, x^{*}\right)[\ln (R H / 100)]^{3} \\
& +e\left(T, x^{*}\right) \ln \left(N_{a}\right)+f\left(T, x^{*}\right) \ln (R H / 100) \ln \left(N_{a}\right) \\
& +g\left(T, x^{*}\right)[\ln (R H / 100)]^{2} \ln \left(N_{a}\right)+h\left(T, x^{*}\right)\left[\ln \left(N_{a}\right)\right]^{2} \\
& \left.+i\left(T, x^{*}\right) \ln (R H / 100)\left[\ln \left(N_{a}\right)\right]^{2}+j\left(T, x^{*}\right)\left[\ln \left(N_{a}\right)\right]^{3}\right\},
\end{aligned}
$$

where the coefficients $a\left(T, x^{*}\right) \ldots i\left(T, x^{*}\right)$ are functions of temperature and critical cluster mole fraction $x^{*}$ (calculated using equation (11)):

$$
\begin{aligned}
& a\left(T, x^{*}\right)=0.14309+2.21956 T-0.0273911 T^{2} \\
& +0.0000722811 T^{3}+\frac{5.91822}{x^{*}} \\
& b\left(T, x^{*}\right)=0.117489+0.462532 T-0.0118059 T^{2} \\
& +0.0000404196 T^{3}+\frac{15.7963}{x^{*}} \\
& c\left(T, x^{*}\right)=-0.215554-0.0810269 T+0.00143581 T^{2} \\
& -4.7758 \cdot 10^{-6} T^{3}-\frac{2.91297}{x^{*}} \\
& d\left(T, x^{*}\right)=-3.58856+0.049508 T-0.00021382 T^{2} \\
& +3.10801 \cdot 10^{-7} T^{3}-\frac{0.0293333}{x^{*}} \\
& e\left(T, x^{*}\right)=1.14598-0.600796 T+0.00864245 T^{2} \\
& -0.0000228947 T^{3}-\frac{8.44985}{x^{*}} \\
& f\left(T, x^{*}\right)=2.15855+0.0808121 T-0.000407382 T^{2} \\
& -4.01957 \cdot 10^{-7} T^{3}+\frac{0.721326}{x^{*}} \\
& g\left(T, x^{*}\right)=1.6241-0.0160106 T+0.0000377124 T^{2} \\
& +3.21794 \cdot 10^{-8} T^{3}-\frac{0.0113255}{x^{*}} \\
& h\left(T, x^{*}\right)=9.71682-0.115048 T+0.000157098 T^{2} \\
& +4.00914 \cdot 10^{-7} T^{3}+\frac{0.71186}{x^{*}} \\
& i\left(T, x^{*}\right)=-1.05611+0.00903378 T-0.0000198417 T^{2} \\
& +2.46048 \cdot 10^{-8} T^{3}-\frac{0.0579087}{x^{*}} \\
& j\left(T, x^{*}\right)=-0.148712+0.00283508 T-9.24619 \cdot 10^{-6} T^{2} \\
& +5.00427 \cdot 10^{-9} T^{3}-\frac{0.0127081}{x^{*}} \text {. }
\end{aligned}
$$

[23] The total number of molecules in the critical cluster $n_{\text {tot }}$ is given by

$$
\begin{aligned}
n_{\mathrm{tot}}= & \exp \left\{A\left(T, x^{*}\right)+B\left(T, x^{*}\right) \ln (R H / 100)\right. \\
& +C\left(T, x^{*}\right)[\ln (R H / 100)]^{2}+D\left(T, x^{*}\right)[\ln (R H / 100)]^{3} \\
& +E\left(T, x^{*}\right) \ln \left(N_{a}\right)+F\left(T, x^{*}\right) \ln (R H / 100) \ln \left(N_{a}\right) \\
& +G\left(T, x^{*}\right)[\ln (R H / 100)]^{2} \ln \left(N_{a}\right)+H\left(T, x^{*}\right)\left[\ln \left(N_{a}\right)\right]^{2} \\
& \left.+I\left(T, x^{*}\right) \ln (R H / 100)\left[\ln \left(N_{a}\right)\right]^{2}+J\left(T, x^{*}\right)\left[\ln \left(N_{a}\right)\right]^{3}\right\},
\end{aligned}
$$

where the coefficients $A\left(T, x^{*}\right) \ldots I\left(T, x^{*}\right)$ again depend on temperature and critical cluster mole fraction $x^{*}$ (from equation (11)):

$$
\begin{aligned}
& A\left(T, x^{*}\right)=-0.00295413-0.0976834 T+0.00102485 T^{2} \\
& -2.18646 \cdot 10^{-6} T^{3}-\frac{0.101717}{x^{*}} \\
& B\left(T, x^{*}\right)=-0.00205064-0.00758504 T+0.000192654 T^{2} \\
& -6.7043 \cdot 10^{-7} T^{3}-\frac{0.255774}{x^{*}} \\
& C\left(T, x^{*}\right)=0.00322308+0.000852637 T-0.0000154757 T^{2} \\
& +5.66661 \cdot 10^{-8} T^{3}+\frac{0.0338444}{x^{*}} \\
& D\left(T, x^{*}\right)=0.0474323-0.000625104 T+2.65066 \cdot 10^{-6} T^{2} \\
& -3.67471 \cdot 10^{-9} T^{3}-\frac{0.000267251}{x^{*}} \\
& E\left(T, x^{*}\right)=-0.0125211+0.00580655 T-0.000101674 T^{2} \\
& +2.88195 \cdot 10^{-7} T^{3}+\frac{0.0942243}{x^{*}} \\
& F\left(T, x^{*}\right)=-0.038546-0.000672316 T+2.60288 \cdot 10^{-6} T^{2} \\
& +1.19416 \cdot 10^{-8} T^{3}-\frac{0.00851515}{x^{*}} \\
& G\left(T, x^{*}\right)=-0.0183749+0.000172072 T-3.71766 \cdot 10^{-7} T^{2} \\
& -5.14875 \cdot 10^{-10} T^{3}+\frac{0.00026866}{x^{*}} \\
& H\left(T, x^{*}\right)=-0.0619974+0.000906958 T-9.11728 \cdot 10^{-7} T^{2} \\
& -5.36796 \cdot 10^{-9} T^{3}-\frac{0.00774234}{x^{*}} \\
& I\left(T, x^{*}\right)=0.0121827-0.00010665 T+2.5346 \cdot 10^{-7} T^{2} \\
& -3.63519 \cdot 10^{-10} T^{3}+\frac{0.000610065}{x^{*}} \\
& J\left(T, x^{*}\right)=0.000320184-0.0000174762 T+6.06504 \cdot 10^{-8} T^{2} \\
& -1.42177 \cdot 10^{-11} T^{3}+\frac{0.000135751}{x^{*}} \text {. }
\end{aligned}
$$

[24] The radius of the cluster in nanometers is given as a function of the mole fraction and the total number of molecules in the cluster:

$r[\mathrm{~nm}]=\exp \left[-1.6524245+0.42316402 x^{*}+0.3346648 \ln \left(n_{\mathrm{tot}}\right)\right]$.

[25] Figure 3 shows a comparison between the theoretical and parameterized nucleation rates. The comparison is made at over 2000 points evenly distributed over the whole validity range of the parametrization, including the boundaries. The ratio of the theoretical over the parameterized nucleation rate $J_{\text {theor }} / J_{\text {param }}$ varies between 0.14 and 6.9. Most of the points are concentrated around the value 1 on the vertical axis representing a perfect fit. The largest deviations occur for high and low nucleation rates close to the boundaries of the validity region. Actually, in the nucleation rate range of roughly $10^{-6}$ to $10^{7} 1 /\left(\mathrm{cm}^{3} \mathrm{~s}\right)$ the parameterization gives correct results within a factor of 3 . The largest deviations correspond to low relative humidities (below 1\%), high sulfuric acid concentrations (above $10^{8} / \mathrm{cm}^{3}$ ) and small critical clusters (below 15 molecules), but no such trends was 


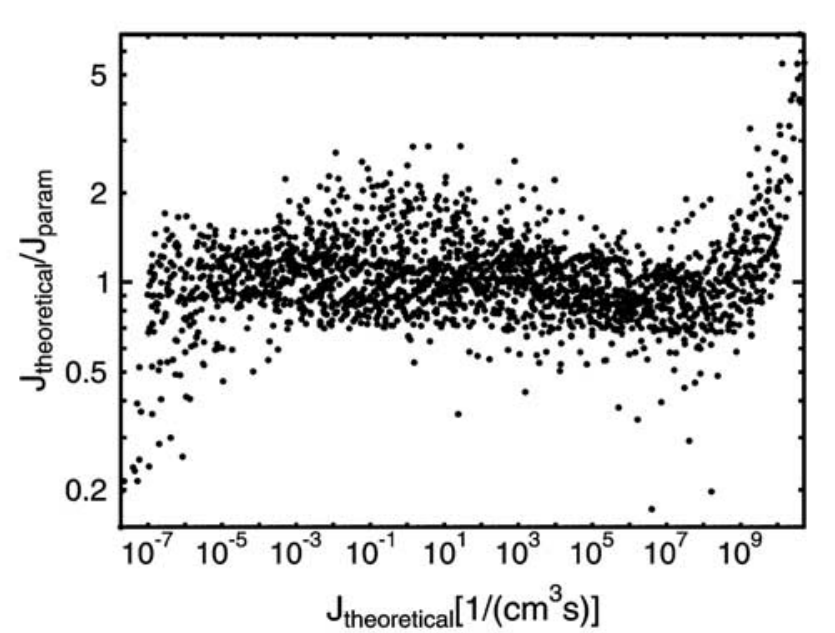

Figure 3. Comparison between the parameterized and the theoretical values for the nucleation rate.

observed for the temperature. The critical cluster mole fraction varies between 0.17 and 0.62 , and the deviation of the fit from the theoretical results $x_{\text {theor }}^{*} x_{\text {param }}^{*}$ ranges from -0.004 to +0.006 as seen in Figure 4. It can be seen that high mole fractions are predicted less accurately than the low ones. The total number of molecules varies between 4 and 70 molecules and the deviation ranges from -0.6 molecules to +1 molecule, and the cluster radius varies between $0.35 \mathrm{~nm}$ and $0.92 \mathrm{~nm}$ and the deviation is between $-0.007 \mathrm{~nm}$ and $+0.001 \mathrm{~nm}$. The comparisons of parameterized number of molecules and radius to the theoretical values are shown in Figures 5 and 6 , respectively. The computing time required by a program using the parameterized nucleation rate is about $0.02 \%(1 /$ 500 ) of the time used by the full theoretical calculation. It should be noted that the activity coefficients of Zeleznik [1991] are already computationally rather fast. Thus, the time saving would be significantly larger if compared to the calculation time using the computationally more demanding activity coefficients by Clegg et al. [1998] as is the case with the ternary parameterization by Napari et al. [2002].

[26] Solving the nonlinear equation (1) for the critical cluster mole fraction is the most time consuming part of the

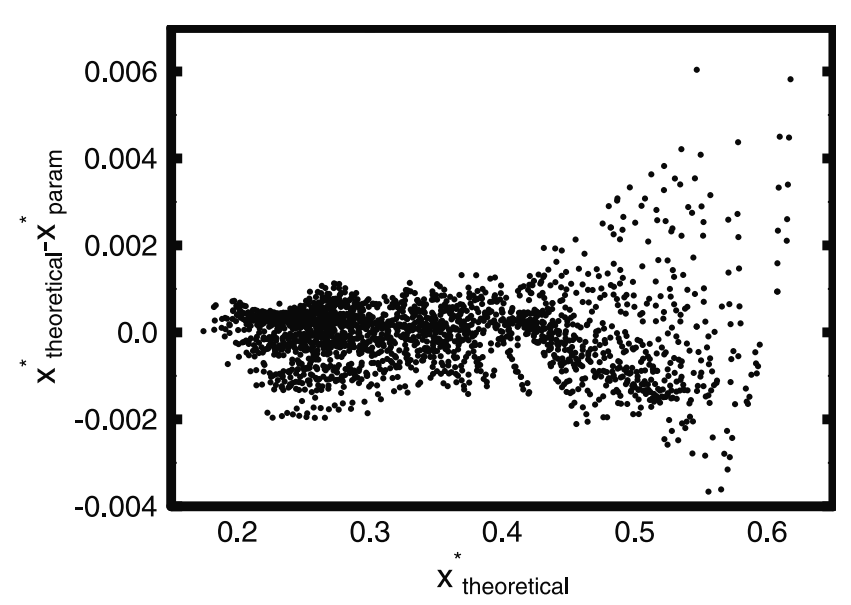

Figure 4. Comparison between the parameterized and the theoretical values for the critical cluster mole fraction.

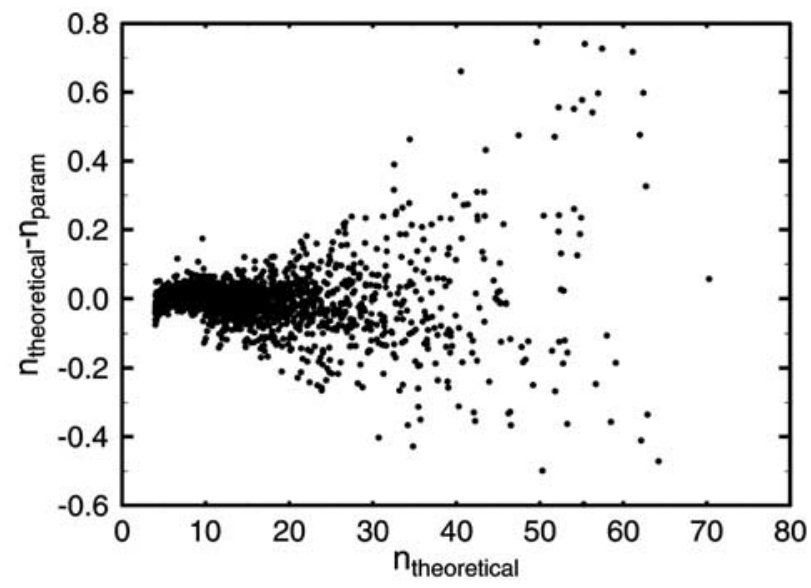

Figure 5. Comparison between the parameterized and the theoretical values for the total number of molecules in the critical cluster.

nucleation rate calculation. A program that uses the parameterized critical mole fraction (equation (11)) instead of solving equation (1), but otherwise has the full theoretical model, requires about $4 \%$ of the time of the full model. The method with only the mole fraction parameterized produces a slightly more accurate result for the nucleation rate than the nucleation rate parameterization, (ratio of nucleation rates between 0.97 and 7.56), but the total number of molecules and the radius of the critical cluster are not estimated any better than with the parameterized equations given above. This method should only be used together with exactly the same model (i.e., the same version of classical model, kinetics, surface tension, density, activities and hydrate description) as was used in this paper, otherwise the result may be severely inaccurate or even unphysical. A slightly modified nucleation model may itself produce results that agree well with our results, but if used together with the mole fraction parameterization presented here the deviations can be drastic. We recommend using the full parametrization in order to avoid compatibility problems.

[27] The threshold concentration $\left(1 / \mathrm{cm}^{3}\right)$ of sulfuric acid (total) that produces the nucleation rate $J=1 /\left(\mathrm{cm}^{3} \mathrm{~s}\right)$

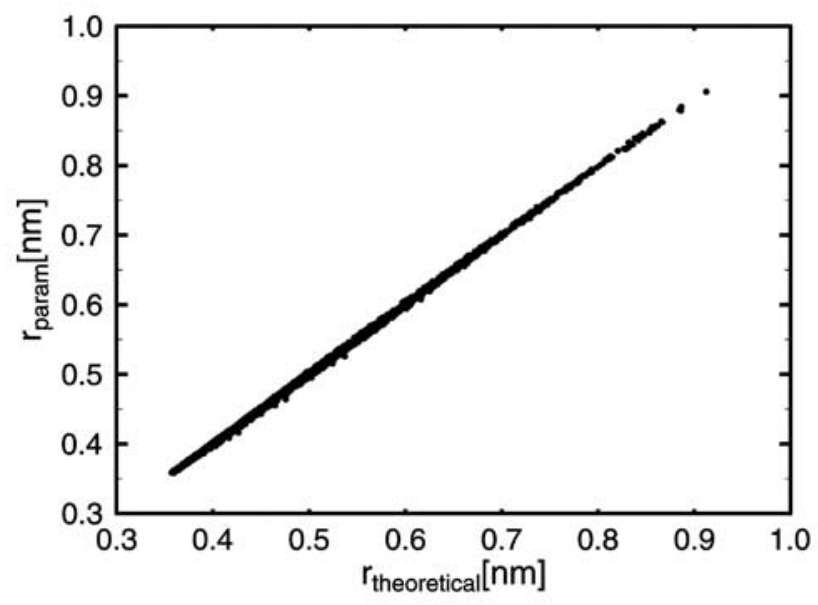

Figure 6. Comparison between the parameterized and the theoretical values for the critical cluster radius. 


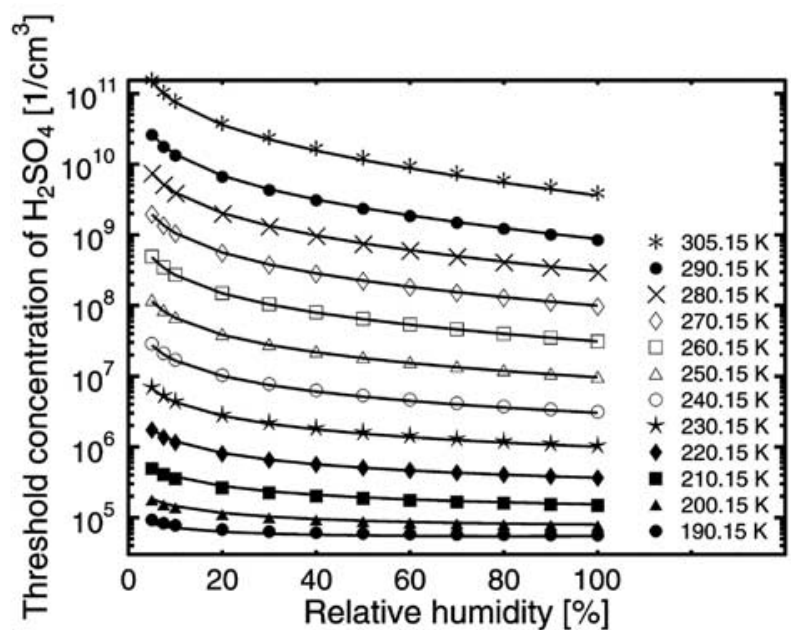

Figure 7. Comparison between the parameterization (equation (15)) (lines) and the theoretical values (symbols) for the threshold sulfuric acid concentration required for nucleation rate $J=1 /\left(\mathrm{cm}^{3} \mathrm{~s}\right)$.

depends on temperature and relative humidity according to the following equation:

$$
\begin{aligned}
& N_{a}^{J=1}\left[1 / \mathrm{cm}^{3}\right]=\exp \left[-279.243+117.344 \frac{R H}{100}\right. \\
& +\frac{22700.9}{T}-\frac{1088.64}{T} \frac{R H}{100}+1.14436 T-0.0302331 \frac{R H}{100} T \\
& \quad-0.00130254 T^{2}-6.38697 \log \left(\frac{R H}{100}\right)+854.98 \log \left(\frac{R H}{100}\right) T \\
& \left.+0.00879662 T \log \left(\frac{R H}{100}\right)\right] .
\end{aligned}
$$

[28] The ratio of the theoretical value to the parameterized value for threshold concentrations varies between 0.93 and 1.13. Figure 7 shows that equation (15) reproduces the threshold concentrations well at the whole temperature range.

\section{Results and Discussion}

[29] Unfortunately there are no experimental thermodynamical or nucleation rate data for stratospheric conditions. However, recently Eisele and Hanson [2000] measured a nucleation rate approximately $10^{6} /\left(\mathrm{cm}^{3} \mathrm{~s}\right)$, at $236 \mathrm{~K}$ and a relative humidity of $55 \%$. Figure 8 compares our results at these conditions with the experimental data point and the old parameterization by Kulmala et al. [1998]. We also show the number of molecules in the critical cluster according to the classical theory. The theory overestimates the nucleation rate by $1-3$ orders of magnitude compared to this experiment at this low temperature. It must be noted that at the experimental conditions of Eisele and Hanson [2000] the applicability of the classical theory is questionable since the predicted critical cluster size is only 4 molecules. The applicability of our parametrization is restricted to critical clusters containing at least four molecules which explains the kink seen in the curve representing the parameterization at sulfuric acid concentration $10 \% / \mathrm{cm}^{3}$. The difference between the old and the new parameterization is not significant at the experimental conditions.

[30] Viisanen et al. [1997] made nucleation rate experiments at $298 \mathrm{~K}$ and two different relative humidities. Ball et al. [1999] measured nucleation rates at $295.15 \mathrm{~K}$ and different relative humidities as a function of sulfuric acid concentration. Figures 9 and 10 show experimental data points with error bars as well as the theoretical and parameterized nucleation rates as a function sulfuric acid concentration. The results of the old parameterization by Kulmala et al. [1998] are shown for comparison. Viisanen et al. [1997] estimate that the nucleation time in their experiments is between $1 \mathrm{~s}$ and $50 \mathrm{~s}$, and they report the maximum sulfuric acid concentrations in the nucleation zone. We estimated that the minimum concentration is 0.6

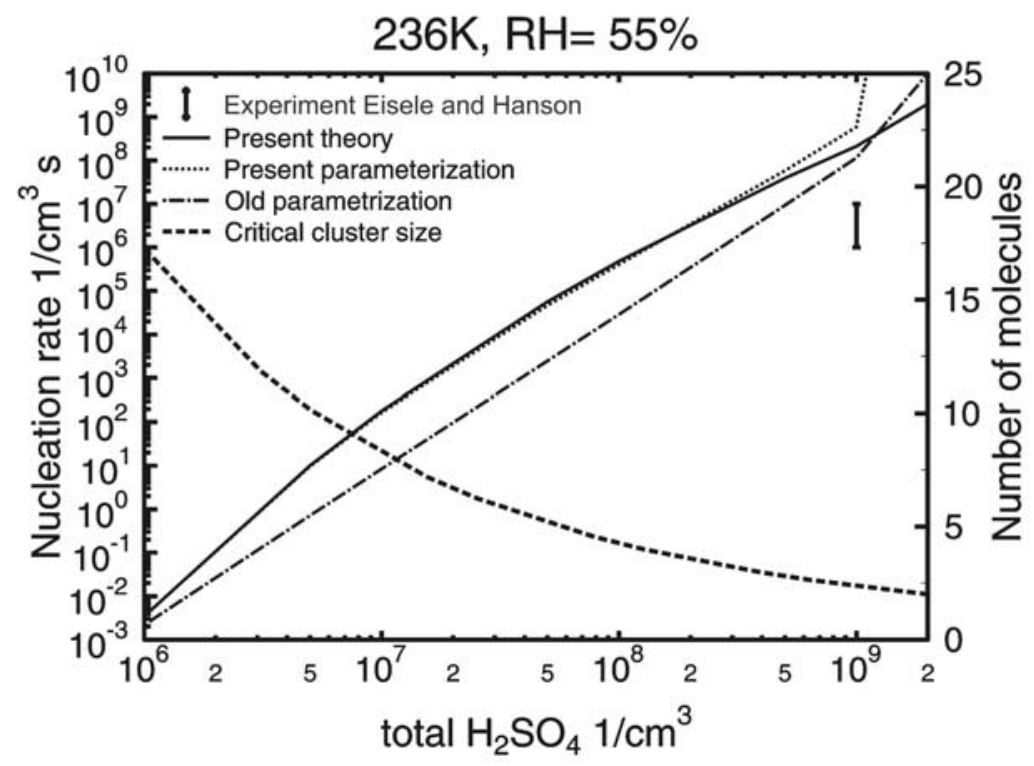

Figure 8. The nucleation rate as a function of total sulfuric acid concentration at $236 \mathrm{~K}$ and relative humidity 55\%. The measurement of Eisele and Hanson [2000] and the results of the old parameterization by Kulmala et al. [1998] are also shown as well as the theoretical predictions for the critical cluster size. 

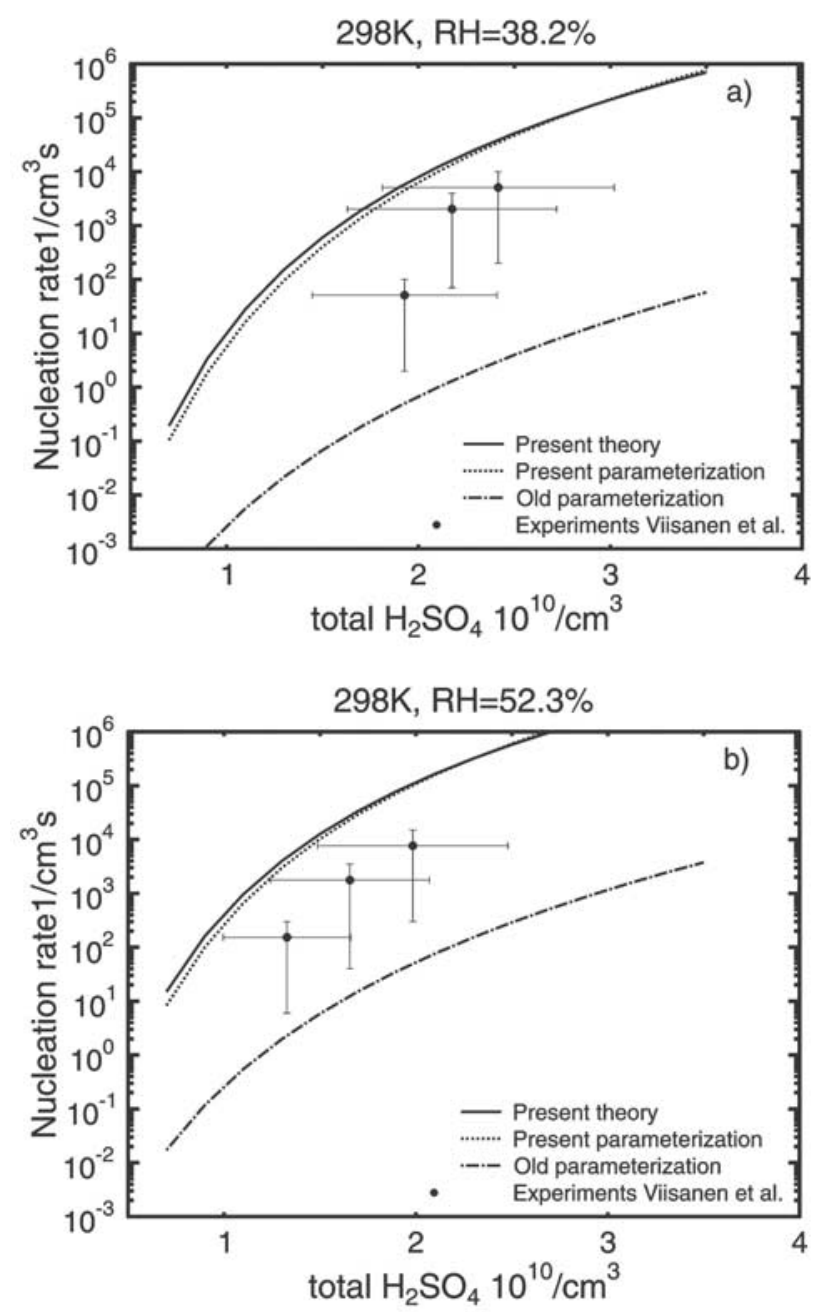

Figure 9. The nucleation rate as a function of total sulfuric acid concentrations at $298 \mathrm{~K}$ and relative humidities (a) $38.2 \%$ and (b) $52.3 \%$. The measurement of Viisanen et al. [1997] and the results of the old parameterization by Kulmala et al. [1998] are also shown.

times the maximum, and calculated error bars of the experimental points in Figure 9 based on these uncertainties in the nucleation time and the sulfuric acid concentration. The experimental point at relative humidity $52.3 \%$ and acid concentration $1.25 \cdot 10^{10} \mathrm{~cm}^{-3}$ is left out due to the large uncertainty of the measured nucleation rate. Ball et al. [1999] estimate that the sulfuric acid concentration in the nucleation zone is $22(-67 \% /+200 \%)$ times higher than the one measured at the end of their chamber. We have indicated this uncertainty as horizontal error bars of the experimental points of Ball et al. [1999] in Figure 10. We only show the results of Ball et al. [1999] for relative humidities $7.5 \%$ and $15.3 \%$ The results for relative humidity $10 \%$ demonstrate a behaviour in between the results for $7.5 \%$ and $15.3 \%$. At the measurements with relative humidities lower than $5 \%$ the nucleation rates are mostly extremely low, and the numerical inaccuracies are of the same order of magnitude as the theoretical results, and comparison with experiments worthless.

[31] If the true sulfuric acid concentrations at the experiments are close to the lower limit of the uncertainty regions and the true nucleation rates are at the higher end, the theory as well as our new parametrization agree well with the experiments around room temperature and relative humidities above $30 \%$. The present parameterization gives consistently clearly higher nucleation rates than the one by Kulmala et al. [1998]. The reasons are differences in the model, most significantly in describing the hydrates, and mistakes in the treatment of the kinetics behind the earlier parameterization. The differences are discussed in detail in our earlier paper [Noppel et al., 2002]. At the experimental conditions of Ball et al. [1999] the relative humidities are lower and the agreement between classical theory (and thus the parametrization) and the experiments is poorer. Comparison between Figures $10 \mathrm{a}$ and $10 \mathrm{~b}$ indicates that the classical theory gives a too strong relative humidity dependence of the nucleation rate compared to the experiments.

[32] The temperature and relative humidity dependence of the theoretical nucleation rate and the parameterization at selected conditions are shown in Figures 11 and 12. These figures illustrate that the parametrization reproduces the
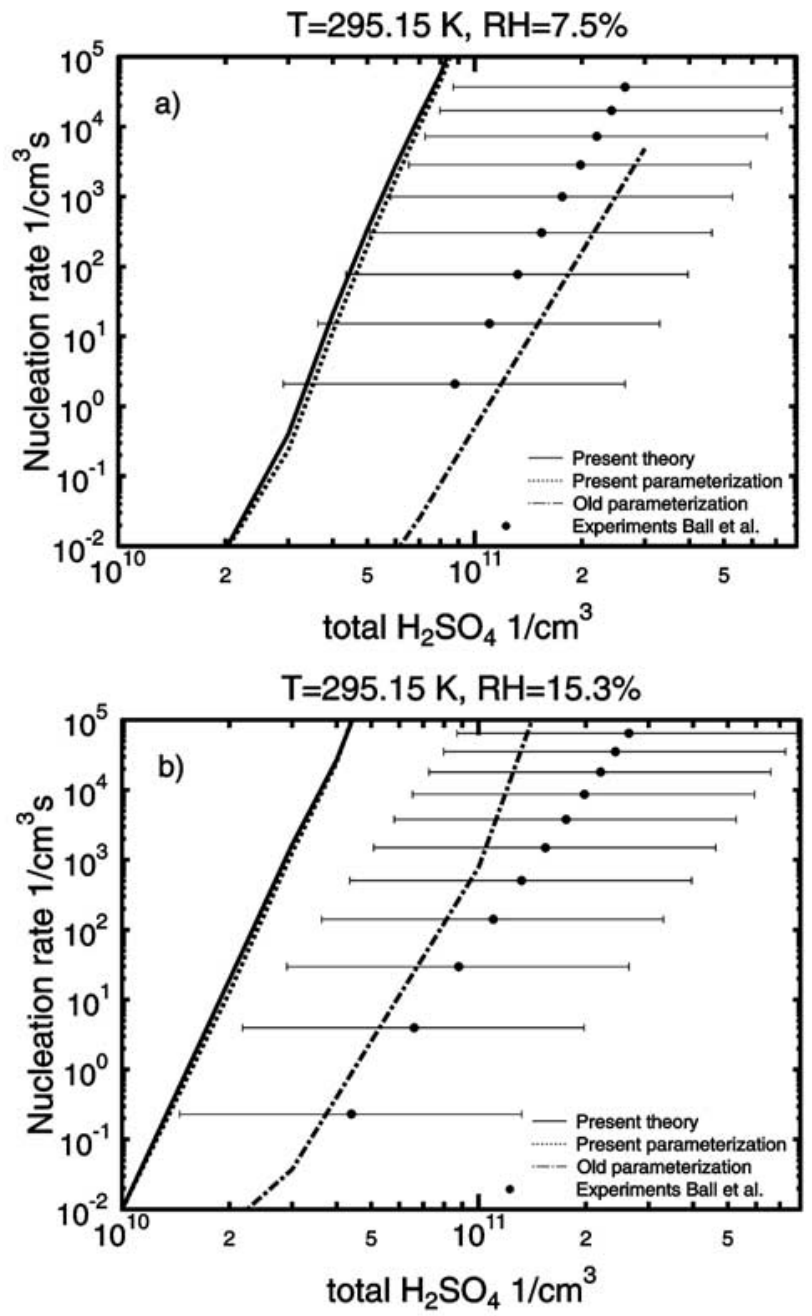

Figure 10. The nucleation rate as a function of total sulfuric acid concentrations at $295.15 \mathrm{~K}$ and relative humidities (a) $7.5 \%$ and (b) $15.3 \%$. The measurement of Ball et al. [1999] and the results of the old parameterization by Kulmala et al. [1998] are also shown. 
temperature and relative humidity dependences of the theoretical nucleation rate well everywhere in the validity region.

\section{Conclusions}

[33] In the present work we have constructed parameterizations for nucleation of sulfuric acid-water mixtures at stratospheric and tropospheric conditions. We also present new expressions for surface tension and density fitted on a wide range of data. The collected density data covers the temperature region $220-300 \mathrm{~K}$, and the surface tension data the region $233-323 \mathrm{~K}$. We present new parameterizations for the critical nucleus composition and radius, number of molecules in the cluster, and homogeneous nucleation rate. We also give an expression for the threshold concentration of sulfuric acid which produces the nucleation rate $1 /\left(\mathrm{cm}^{3} \mathrm{~s}\right)$. The parametrization reproduces the nucleation rate given by the classical theory well within order of magnitude in the range of nucleation rates $10^{-7}-10^{10} /\left(\mathrm{cm}^{3} \mathrm{~s}\right)$ at temperatures $190.15-305.15 \mathrm{~K}$. Below $230 \mathrm{~K}$ the nucleation rates are merely extrapolations from the higher temperatures since these low temperatures are outside the experimentally confirmed validity regions of the thermodynamic parameterizations. The validity of the fit is restricted to cases where the total number of molecules in the critical cluster is at least four. The present nucleation model and parameterization produces nucleation rates $1-4$ orders of magnitude higher than the earlier parameterization [Kulmala et al., 1998]. The validity region of the new parametrization is larger than that of the old one, including lower temperatures, lower relative humidities and a wider range of nucleation rates. Our parameterization can therefore be applied over the whole atmosphere. We recommend the use of our parameterizations in large-scale models since they reduce the required computer time significantly, at least by a factor of $1 / 500$.

[34] The nucleation rates calculated using the classical theory and thus the parameterization are within experimental region at room temperature and relatively high humidities. At low temperatures and/or relative humidities the

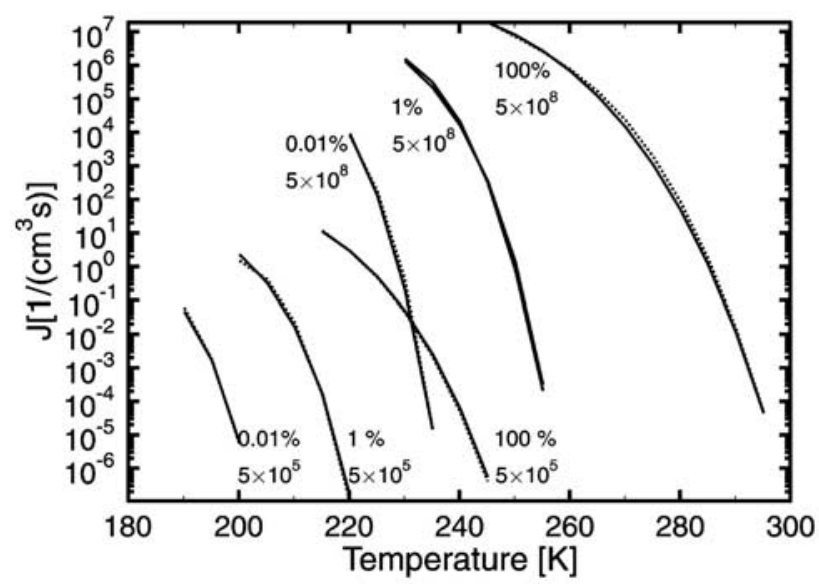

Figure 11. The nucleation rate as a function of temperature at different total sulfuric acid concentrations and relative humidities. The relative humidities and the sulfuric acid concentrations $\left[1 / \mathrm{cm}^{3}\right]$ are marked by the curves. The dashed lines show the parameterized rates, and the solid lines show the theoretical values.

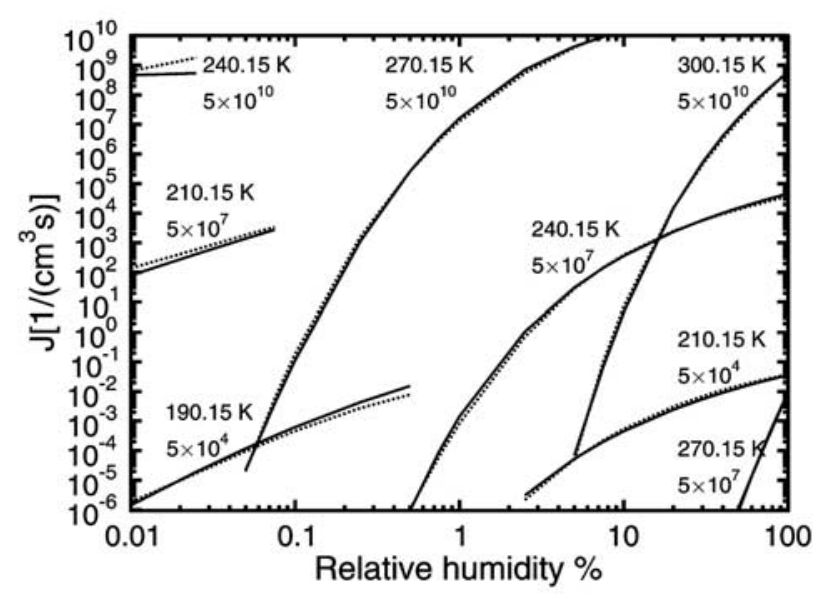

Figure 12. The nucleation rate as a function of relative humidity at different total sulfuric acid concentrations and temperatures. The temperature and the sulfuric acid concentrations $\left[1 / \mathrm{cm}^{3}\right]$ are marked by the curves. The dashed lines show the parameterized rates, and the solid lines show the theoretical values.

deviation from experiments is somewhat larger, and the dependence of theoretical nucleation rate on relative humidity differs from the observed one. At low temperatures the critical clusters are often very small, and the classical approach based on the capillarity approximation is expected to fail. Extensive molecular level studies are needed to pin down the reasons for the failure of the classical theory to predict the observed nucleation rates.

[35] Acknowledgments. This work was supported by the European Commission under contract EVK-2002, project PARTS, Academy of Finland (project 47668) and the Bundesministerium für Bildung, Forschung und Technologie.

\section{References}

Alberty, R., Physical Chemistry, 6th ed., John Wiley, New York, 1983.

Arstila, H., K. Laasonen, and A. Laaksonen, Ab initio study of gas-phase sulphuric acid hydrates containing 1 to 3 water molecules, J. Chem. Phys., 108, 1031-1039, 1998.

Arstila, H., P. Korhonen, and M. Kulmala, Ternary nucleation: Kinetics and application to water-ammonia-hydrochloric acid system, J. Aerosol Sci., 30, 131-138, 1999 .

Ayers, G. P., R. W. Gillett, and J. L. Gras, On the vapor pressure of sulfuric acid, Geophys. Res. Lett., 7, 433-436, 1980.

Ball, S. M., D. R. Hanson, and F. L. Eisele, Laboratory studies of particle nucleation: Initial results for $\mathrm{H}_{2} \mathrm{SO}_{4}, \mathrm{H}_{2} \mathrm{O}$, and $\mathrm{NH}_{4}$ vapor, J. Geophys. Res., 104, 23,709-23,718, 1999.

Bekki, S., and J. A. Pyle, Two-dimensional assessment of the impact of aircraft sulphur emissions on the stratospheric sulphate aerosol layer, J. Geophys. Res., 97, 15,839-15,847, 1992.

Brock, C. A., J. C. Wilson, H. H. Jonsson, and K. R. Chan, Particle formation in the upper tropical troposphere: A source of nuclei for the stratospheric aerosol, Science, 270, 1650-1653, 1995.

Clarke, A., Atmospheric nuclei in the remote free troposphere, J. Atmos. Chem., 14, 479-488, 1992.

Clarke, A. D., Atmospheric nuclei in pacific midtroposphere: Their nature, concentration and evolution, J. Geophys. Res., 98, 20,633-20,647, 1993.

Clegg, S. L., and P. Brimblecombe, Application of a multicomponent thermodynamic model to activities and thermal properties of $0-40 \mathrm{~mol} \mathrm{~kg}-1$ aqueous sulfuric acid from $<200$ to 328 K, J. Chem. Eng. Data, 40, $43-$ 64, 1995.

Clegg, S. L., P. Brimblecombe, and A. S. Wexler, A thermodynamic model of the system $\mathrm{H}-\mathrm{NH}_{4}-\mathrm{SO}_{4}-\mathrm{NO}_{3}-\mathrm{H}_{2} \mathrm{O}$ at tropospheric temperatures, J. Phys. Chem. A, 102, 2137-2154, 1998.

Clement, C. F., I. Ford, C. H. Twohy, A. J. Weinheimer, and T. Campos, 
Particle production in the outflow of a midlatitude storm, J. Geophys. Res., 107, doi:10.1029/2001JD001352, in press, 2002.

Covert, D. S., V. N. Kapustin, P. K. Quinn, and T. S. Bates, New particle formation in the marine boundary layer, J. Geophys. Res., 97, 20,58120,589, 1992.

De Reus, M., J. Strm, M. Kulmala, L. Pirjola, J. Lelieveld, C. Schiller, and M. Zger, Airbone aerosol measurements in the tropopause region and the dependence of new particle formation on pre-existing particle number concentration, J. Geophys. Res., 103, 31,255-31,263, 1998.

Deshler, T., D. J. Hofmann, B. J. Johnson, and W. R. Rozie, Balloonborne measurements of the Pinatubo aerosol size distribution and volatility at Laramie, Wyoming during the summer of 1991, Geophys. Res. Lett., 19, 199-202, 1992.

Deshler, T., B. J. Johnson, and W. R. Rozie, Balloonborne measurements of Pinatubo aerosol during 1991 and 1992 at $41^{\circ}$ : Vertical profiles, size distribution, and volatility, Geophys. Res. Lett., 20, 1435-1438, 1993.

Eisele, F. L., and D. R. Hanson, First measurements of prenucleation molecular clusters, J. Phys. Chem. A, 104, 830-836, 2000.

Hegg, D., L. Radke, and P. Hobbs, Measurements of Aitken nuclei and cloud condensation nuclei in the marine atmosphere and their relation to the DMS-cloud-climate hypothesis, J. Geophys. Res., 96, 18,727$18,733,1991$

Hoffmann, W., and F. W. Seeman, Schwefelsäure-Wasser gemischen im Temperaturbereich von 15 bis 25 C, Z. Physik. Chem. Neue Folge, 24, 300-306, 1960.

Hoppel, W. A., G. M. Frick, J. W. Fitzgerald, and R. E. Larson, Marine boundary layer measurements of new particle formation and the effects nonprecipitating clouds have on aerosol size distribution, J. Geophys. Res., 99, 14,443-14,459, 1994.

Jaecker-Voirol, A., P. Mirabel, and H. Reiss, Hydrates in supersatured binary sulfuric acid-water vapor: A reexamination, J. Chem. Phys., 87, 4849-4852, 1987.

Kavouras, I., N. Mihalopoulos, and E. Stephanou, Formation of atmospheric particles from organic acids produced by forests, Nature, 395, 686-693, 1998.

Korhonen, P., M. Kulmala, and Y. Viisanen, A theoretical study of binary homogeneous nucleation of water-ammonium chloride particles in the atmosphere, J. Aerosol Sci., 28, 901-917, 1997.

Korhonen, P., M. Kulmala, A. Laaksonen, Y. Viisanen, R. McGraw, and J. Seinfeld, Ternary nucleation of $\mathrm{H}_{2} \mathrm{SO}_{4}, \mathrm{NH}_{3}$ and $\mathrm{H}_{2} \mathrm{O}$ in the atmosphere, J. Geophys. Res., 104, 26,349-26,353, 1999.

Kulmala, M., and A. Laaksonen, Binary nucleation of water-sulfuric acid system: Comparison of classical theories with different $\mathrm{H}_{2} \mathrm{SO}_{4}$ saturation vapor pressures, J. Chem. Phys., 93, 696-701, 1990.

Kulmala, M., A. Laaksonen, and L. Pirjola, Parametrizations for sulfuric acid/water nucleation rates, J. Geophys. Res., 103, 8301-8308, 1998.

Kulmala, M., L. Pirjola, and J. M. Mäkelä, Stable sulphate clusters as a source of new atmospheric particles, Nature, 404, 66-69, 2000.

Kulmala, M., et al., Overview of the international project on biogenic aerosol formation in the boreal forest (BIOFOR), Tellus, Ser. B, 53, 324-343, 2001

Kusaka, I., Z.-G. Wang, and J. H. Seinfeld, Direct evaluation of the equilibrium distribution of physical clusters by a grand canonical Monte Carlo simulation, J. Chem. Phys., 108, 3416-3423, 1998.

Laaksonen, A., and D. W. Oxtoby, Gas-liquid nucleation of nonideal binary mixtures, I, A density functional study, J. Chem. Phys., 102, 5803-5810, 1995.

Morgan, L. J., and C. E. Davies, The properites of mixed liquids I, Sulfuric acid-water mixtures, J. Am. Chem. Soc., 28, 555-568, 1916.

Myhre, C. E. L., C. J. Nielsen, and O. W. Saastad, Density and surface tension of aqueous $\mathrm{H}_{2} \mathrm{SO}_{4}$ at low temperatures, J. Chem. Eng. Data, 43, 617-622, 1998.

Napari, I., M. Noppel, H. Vehkamäki, and M. Kulmala, Parametrization of ternary nucleation rates for $\mathrm{H}_{2} \mathrm{SO}_{4}-\mathrm{NH}_{3}-\mathrm{H}_{2} \mathrm{O}$ vapors, J. Geophys. Res., 107(D19), 4381, doi:10.1029/2002JD002132, 2002.

National Research Council, International Critical Tables of Numerical Data Physics, Chemistry and Technology, vol. 1, pp. 56-57, McGrawHill, New York, 1928.

Noppel, M., Binary nucleation of water-sulfuric acid system: A revision of the classical hydrates interaction model, J. Chem. Phys., 109, 90529056, 1998.

Noppel, M., Enthalpy and entropy changes in formation of gas phase sulfuric acid monohydrates and dihydrates as a result of fitting to experimental pressure data, J. Geophys. Res., 105, 19,779-19,785, 2000.

Noppel, M., H. Vehkamäki, and M. Kulmala, An improved model for hydrate formation in sulfuric-acid water nucleation, J. Chem. Phys, 116, 218-228, 2002.

O’Dowd, C., M. Geever, M. Hill, M. Smith, and S. Jennings, New particle formation: Nucleation rates and spatial scales in the clean marine coastal environment, Geophys. Res. Lett., 25, 1661-1664, 1998.
Pirjola, L., A. Laaksonen, P. Aalto, and M. Kulmala, Sulfate aerosol formation in the arctic boundary layer, J. Geophys. Res., 103, 8309-8322, 1998. Pitari, G., E. Mancini, V. Rizi, and D. T. Shindel, Impact of future climate and emission changes on stratospheric aerosols and ozone, J. Atmos. Sci., 59, 414-440, 2002

Preining, O., P. E. Wagner, F. G. Pohl, W. Szymanski, Heterogeneous nucleation and droplet growth, report, Inst. of Exp. Phys., Univ. of Vienna, 1981.

Sabinina, L., and L. Terpugow, Die Oberflächenspannung des Systems Schwefelsure-Wasser, Z. Phys. Chem., Abt. A, 173, 237-241, 1935.

Schell, B., I. J. Ackermann, H. Hass, F. S. Binkowski, and A. Ebel, Modelling the formation of secondary organic aerosol within a comprehensive air quality model system, J. Geophys. Res., 106, 28,27528,293, 2001.

Schröder, F., and J. Ström, Aircraft measurements of submicrometer aerosol particles $(>7 \mathrm{~nm})$ in the midlatitude free troposphere and tropopause region, J. Atmos. Res., 44, 333-356, 1997.

Seinfeld, J. H., and S. N. Pandis, Atmospheric Chemistry and Physics: From Air Pollution to Climate Change, John Wiley, New York, 1998.

Shaw, G., Production of condensation nuclei in clean air by nucleation of $\mathrm{H}_{2} \mathrm{SO}_{4}$, Atmos. Environ, 23, 2841-2846, 1989.

Sheridan, P. J., R. C. Schnell, D. J. Hofmann, and T. Deshle, Electron microscope studies of Mt. Pinatubo aerosol layers over Laramie, Wyoming, during summer 1991, Geophys. Res. Lett., 19, 203-206, 1992.

Suggitt, R. M., P. M. Aziz, and F. W. Wetmor, The surface tension of aqueous sulfuric acid solutions at $25^{\circ}, \mathrm{J}$. Am. Chem. Soc., 71, 676$678,1949$.

Taleb, D.-E., J.-L. Ponche, and P. Mirabel, Vapor pressures in the ternary system water-nitric acid-sulfuric acid at low temperature: A reexamination, J. Geophys. Res., 101, 25,967-25,977, 1996.

Tie, X., G. P. Brasseur, B. Briegleb, and C. Graine, Two-dimensional simulation of Pinatubo aerosol and its effect on stratospheric ozone, J. Geophys. Res., 99, 20,545-20,562, 1994.

Timmreck, C., Three-dimensional simulation of stratospheric background aerosol: First results of a multiannual general circulation model simulation, J. Geophys. Res., 106, 28,313-28,332, 2001.

Trinkaus, H., Theory of the nucleation of multicomponent precipitates, Phys. Rev.B., 27, 7372-7378, 1983.

Twohy, C. H., C. F. Clement, B. W. Gandrud, A. J. Weinheimer, T. Campos, D. Baumgardner, W. H. Brune, G. W. Sachse, and S. A. Vay, Deep convection as a source of new particles in the midlatitude upper troposhere, J. Geophys. Res., 107, doi:10.1029/2001JD000323, in press, 2002.

Viisanen, Y., M. Kulmala, and A. Laaksonen, Experiments on gas-liquid nucleation of sulfuric acid and water, J. Chem. Phys., 107, 920-926, 1997.

Weisenstein, D. K., G. K. Yue, M. K. W. Ko, N.-D. Sze, J. M. Rodriguez, and C. J. Scot, A two-dimensional model of sulfur species and aerosol, J. Geophys. Res., 102, 13,019-13,053, 1997.

Wiedensohler, A., D. Covert, E. Swietlicki, P. Aalto, J. Heinzenberg, and C. Leck, Occurrence of an ultrafine particle mode less than $20 \mathrm{~nm}$ in diameter in the marine boundary layer during arctic summer and autumn, Tellus, Ser. B, 48, 213-222, 1996.

Wiedensohler, A., et al., Night-time formation and occurrence of new particles associated with orographic cloud, Atmos. Environ., 31, 2545-2559, 1997.

Wilson, J. C., M. Loewenstein, D. W. Fahey, B. Gary, S. D. Smith, K. K. Kelly, G. V. Ferry, and K. R. Chan, Observations of condensation nuclei in the airborne arctic ozone experiment: Implications for new particle formation and polar stratospheric cloud formation, J. Geophys. Res., 94, 16,437-16,448, 1989.

Wilson, J., C. Cuvelier, and F. Raes, A modeling study of global mixed aerosol fields, J. Geophys. Res., 106, 34,081-34,108, 2001.

Zeleznik, F. J., Thermodynamic properties of the aqueous sulfuric acid system to 350 K, J. Phys. Chem. Ref. Data, 20, 1157-1200, 1991.

M. Kulmala, K. E. J. Lehtinen, I. Napari, and H. Vehkamäki, Laboratory of Aerosol and Environmental Physics, Department of Physical Sciences, University of Helsinki, P. O. Box 64, (Gustaf Hällströmin katu 2), FIN00014 University of Helsinki, Finland. (markku.kulmala@helsinki.fi; hanna.vehkamaki@helsinki.fi)

A. Laaksonen, Department of Applied Physics, University of Kuopio, P. O. Box 1627, FIN-70211 Kuopio, Finland. (ari.laaksonen@uku.fi)

M. Noppel, Institute of Environmental Physics, University of Tartu, 18 Ülikooli Str., 50090 Tartu, Estonia. (madis.noppel@ut.ee)

C. Timmreck, Max-Planck Institut für Meteorologie, Bundesstr. 55, D-20146 Hamburg, Germany. (timmreck@dkrz.de) 